\title{
Cyproterone acetate reduced antler growth in surgically castrated fallow deer
}

\author{
L Bartoš ${ }^{1}$, D Schams ${ }^{2}$, U Kierdorf ${ }^{3}$, K Fischer $^{4}$, GA Bubenik ${ }^{5}$, \\ J Šiler ${ }^{1}$, S Losos ${ }^{1}, \mathbf{M}$ Tománek ${ }^{1}$ and J Laštovková ${ }^{1}$ \\ ${ }^{1}$ Research Institute of Animal Production, CZ-104 00 Praha 10-Uhříněves, Czech Republic \\ ${ }^{2}$ Institute of Physiology, University of Munich-Weihenstephan, D-85354 Freising-Weihenstephan, Germany \\ ${ }^{3}$ Institute of General and Systematic Zoology, Justus-Liebig-University of Giessen, Giessen, Germany \\ ${ }^{4}$ University of Göttingen, D-3400 Göttingen, Germany \\ ${ }^{5}$ University of Guelph, Guelph, Ontario N1G 2W1, Canada \\ (Requests for offprints should be addressed to L Bartoš, Ethology Group, Research Institute of Animal Production, P.O. Box 1, CZ-104 00 Praha 10-Uhříněves, \\ Czech Republic. Email: bartos@uuzv.cz)
}

\begin{abstract}
We studied the role of androgens in antler growth. In particular, we investigated whether the onset of antler regrowth is triggered by a short-term pulse of testosterone and if low levels of androgens are required for antler growth. The study was conducted on 12 surgically castrated fallow deer bucks (Dama dama) aged approximately 27 months. Six animals (CA group) were given the antiandrogen, cyproterone acetate (CA, $1000 \mathrm{mg}$ / treatment); the others were given vehicle solution only (control). Before each CA treatment, blood was sampled and analysed for testosterone, androstenedione, IGF-1, cortisol, FSH, and LH. CA treatment and blood sampling were performed 2 days before castration, on the day of castration and afterwards at 2-day intervals until day 22 . Subsequently, CA treatment and blood sampling continued at weekly intervals until day 270. All animals cast their antlers, followed by antler regrowth in all control bucks, but in only four of the six CA-treated castrates. Plasma testosterone concentrations were low in all animals (between 0.01 and $0.20 \mathrm{ng} / \mathrm{ml}$ ), but were significantly $(P<0001)$ greater in the controls. In both groups, a temporary increase in testosterone values was recorded around the time of antler regrowth, the peak being significantly $(P<0 \cdot 01)$ higher in the controls. Andro-
\end{abstract}

stenedione showed a similar pattern as testosterone. Plasma IGF-1 concentrations increased sharply during the antler growth spurt and did not differ significantly between the two groups throughout the study period. Cortisol concentrations were greater in controls than in the CA group. However, no link with the antler cycle was apparent. FSH and $\mathrm{LH}$ concentrations were higher in the controls for most of the study. Antlers produced by the control bucks were significantly larger than those in the CA group $(P<0 \cdot 03)$. For antler length, testosterone, androstenedione and IGF-1, areas under the curve (AUC) were calculated over the period of antler growth. For the pooled deer $(n=12)$ significant correlations existed between AUCs of antler length and testosterone, but not for antler length and IGF-1. Also, a trend for a positive correlation between AUCs of antler length and androstenedione was noted. It is concluded that a plasma androgen concentration at least above a minimal threshold level is a necessary prerequisite for normal antler regrowth in fallow deer, and that this androgen effect is not mediated via circulating IGF-1. The biological role of low levels of androgens may be to sensitize antler cells to the stimulating effect of IGF.

Journal of Endocrinology (2000) 164, 87-95

\section{Introduction}

Deer antlers are unique biological structures that, except for reindeer, constitute male secondary sexual characteristics. Antlers are periodically cast and regrown (Goss 1983) and in most species, including the fallow deer (Fig. 1, Rolf \& Fischer 1990), the annual antler cycle is basically associated with seasonal changes in circulating androgen concentrations. The precise role of androgens in antler growth has for long been, and still is, a matter of controversy. Over the years, a number of in vivo and in vitro studies (e.g. Suttie et al. 1994, Sadighi et al. 1994, Elliott et al. 1996, Li et al. 1999) have been performed that addressed this question using varying methods.

On the basis of more or less indirect evidence, some authors suggested that small concentrations of circulating androgens are required to stimulate antler growth or that the onset of an antler regrowth is triggered by a shortterm pulse of testosterone, or both (Bartoš 1980, Bubenik 1982, Sempéré \& Boissin 1982). The reports of a 


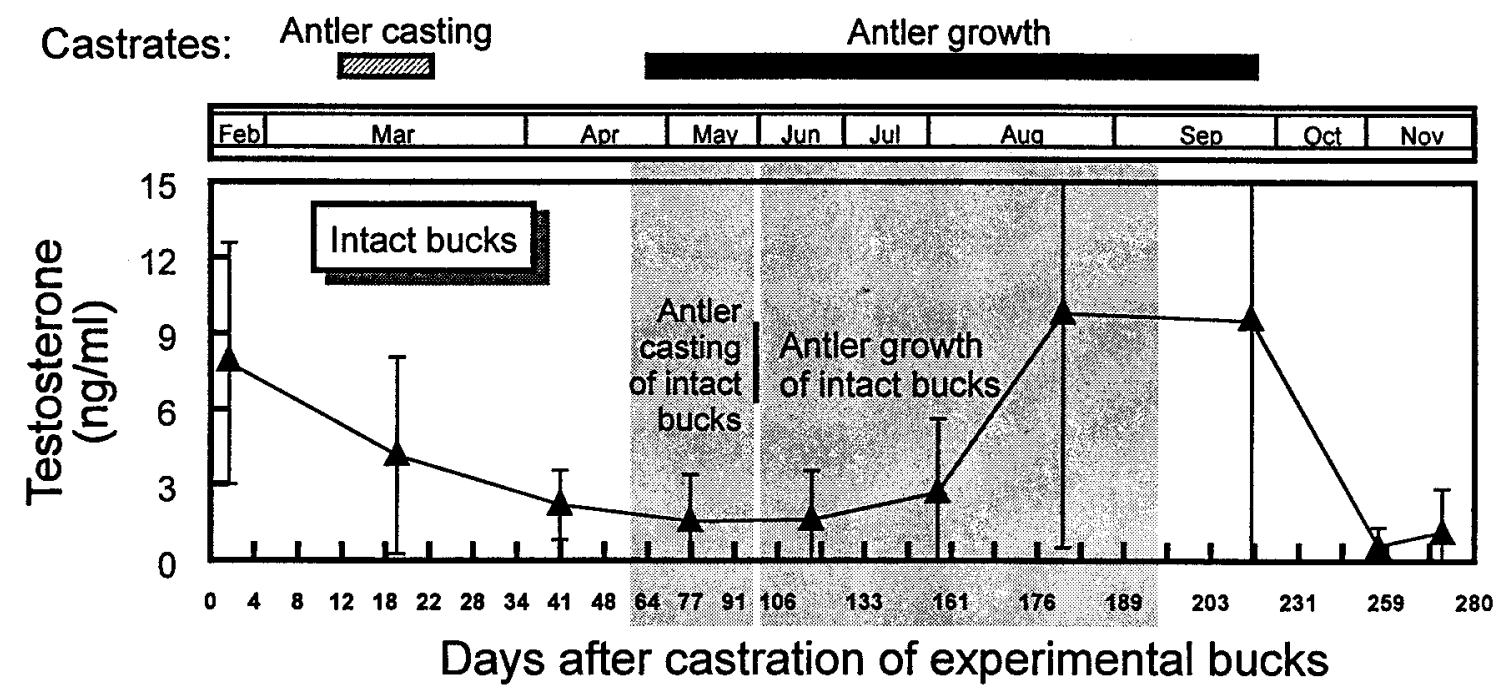

Figure 1 Annual cycle of testosterone concentrations (mean \pm S.E.) and antler cycle of a group of six intact fallow deer bucks aged 3 years (adapted from Rolf \& Fischer 1990). Timing of antler casting and regrowth by the castrated bucks in the present study is indicated above the figure.

secondary peak in testosterone concentrations detected during spring in a number of deer species (for review see Bartoš 1990) were seen as proof of this hypothesis. The same applies to the observation by Brown et al. (1978) of a positive correlation between serum androgen concentrations in white-tailed bucks during the early phase of antler regrowth and antler mass increase. Moreover, Bubenik (1982, 1990) reported that treatment with the antiandrogen, cyproterone acetate (CA), completely stopped antler growth in castrated white-tailed bucks. Conversely, series of experiments have been performed, the results of which called into question the validity of the above hypothesis as to the promoting role of androgens in antler regrowth. Thus Schams et al. (1986) found that CA treatment did not inhibit antler growth in intact roe bucks, but only delayed velvet shedding until after the end of the treatment. Antler growth in the bucks ceased in April that is, at the normal time for the species. Also, CA treatment, while inducing out of season antler casting, did not prevent antler growth or the attainment of speciesspecific antler shape in intact fallow bucks (Kierdorf et al. 1993, Kolle et al. 1993) and red deer stags (Suttie et al. 1995). Antlers grown by the CA-treated red deer were even larger than those of the untreated controls (Suttie et al. 1995).

On the basis of the above in vivo results, it was concluded that velvet antler growth does not require testosterone stimulation, whereas the timing of the antler cycle is linked to the seasonal variations in testosterone concentrations (Kierdorf et al. 1993, Kolle et al. 1993, Suttie et al. 1995). Suttie et al. (1992) even stated that the stag can be considered almost a functional castrate for the first few weeks of velvet antler growth.

In all of the above-mentioned studies, the detection limit for testosterone was $0 \cdot 1 \mathrm{ng} / \mathrm{ml}$ plasma. Therefore the question of a possible biological function of testosterone at concentrations less than or near to $0.1 \mathrm{ng} / \mathrm{ml}$ could not have been addressed. Some time ago, Rivest et al. (1981) demonstrated that alterations of various biological processes are triggered by the fluctuation of the day length regardless of the light intensity. Thus, analogically, if there was any variation in testosterone to less than $0 \cdot 1 \mathrm{ng} / \mathrm{ml}$, androgens still might have been of biological relevance, as the sensitivity of androgen receptors is enhanced during the period of low circulating concentrations.

On the basis of this reasoning, we decided to test experimentally the role of low levels of androgens on antler growth in fallow deer by comparing castrated fallow bucks with castrates treated with high doses of CA. High doses of CA were given in order to block the action of androgens of adrenal origin, concomitant with the suppression of gonadotrophin production by the pituitary in the bucks (cf. Neumann 1994). We tested the following two hypotheses:

1. If a new antler growth is induced by a short-term pulse of testosterone, then such a pulse should be detected in animals producing antlers even at concentrations less than $0 \cdot 1 \mathrm{ng} / \mathrm{ml}$.

2. If androgens were required for antler growth, then the CA-treated castrates should not produce antlers at all, or only a reduced antler growth should be observed, as compared with the controls. 


\section{Materials and Methods}

\section{Animals}

Twelve fallow deer bucks, aged approximately 27 months at the start of the experiment, were divided in two groups of six animals each. One month before the experiment, the bucks were transferred to indoor rooms (each $6 \times 3 \mathrm{~m}$ ). The rooms were illuminated through windows and no additional light sources were used except for the periods when the animals were manipulated. While indoors, the animals were fed hay (available ad libitum), potatoes, beet, or both $(2 \mathrm{~kg} /$ animal per day), and barley $(0 \cdot 75 \mathrm{~kg} /$ animal per day). After being released outdoors, the deer were fed on grass supplemented with barley $(0.75 \mathrm{~kg} /$ animal per day) and hay. On 24 February (day 0), all animals were darted with a 1:1 mixture of xylazine and ketamine $(2 \mathrm{ml})$ and then surgically castrated. Wound healing was complete and uneventful in all animals.

\section{CA treatment, blood sampling and measurement of antler growth}

Cyproterone acetate, a generous gift from Schering AG, Berlin, Germany, was dissolved in benzyl benzoate at $170{ }^{\circ} \mathrm{C}$. One part of this solution was mixed with three parts of preheated $\left(150{ }^{\circ} \mathrm{C}\right)$ castor oil (Kierdorf et al. 1993). After cooling to body temperature, CA (1000 mg/animal) was delivered as a $7 \mathrm{ml}$ intramuscular injection into the hind limb of the bucks from the CA group. Animals from the control group received $7 \mathrm{ml}$ of vehicle solution only. Treatments were performed 2 days before castration, on the day of castration and afterwards at 2-day intervals until day 22, when all the animals had cast their antlers. Blood samples for hormone analyses were taken before the treatment, 2 days before castration, on the day of castration and then at every second treatment until day 22. Thereafter, both treatment and blood sampling were continued at weekly intervals. For the treatment and blood sampling, the animals were manually restrained. On day 106, all animals were released into outside paddocks. Subsequently, all handling was done using a crush. During handling, the bucks were inspected for signs of an antler regrowth and, after onset of antler growth, antler length was measured from the base of the coronet to the antler tip. The values indicated and used for calculation, respectively, were means of the antler lengths from both sides. (Other antler parameters such as changes in diameter could not be followed precisely, because of a slightly malformed shape of the antlers.) After cessation of antler elongation (day 217), treatment with CA or vehicle solution was stopped.

\section{Hormone analyses}

Concentrations of testosterone, cortisol, insulin like growth factor 1 (IGF-1), follicle stimulating hormone
(FSH), and luteinizing hormone (LH) were determined in plasma by enzyme immunoassay (EIA) or radioimmunoassay (RIA). For each hormone, all samples were assayed at the same time.

Testosterone was measured by EIA (Blottner et al. 1996) with a double antibody technique after extraction of $1 \mathrm{ml}$ plasma with $3 \mathrm{ml}$ tertiary butylmethyletherpetrolether $30: 70(\mathrm{v} / \mathrm{v})$. After freezing, the solvent fraction was decanted and evaporated in a water bath at $60{ }^{\circ} \mathrm{C}$. The extract was dissolved in $100 \mu \mathrm{l}$ assay buffer, and $20 \mu \mathrm{l} /$ tube were analysed. The assay used a polyclonal antibody raised in a rabbit against testosterone-11hemisuccinate-BSA, and the label was testosterone3-carboxy methyl-oxime-horseradish peroxidase. Cross reactivities were: testosterone $100 \%, 5 \alpha$-dihydrotestosterone $10 \%$, androstendione $2 \%$, oestradiol $<0 \cdot 1 \%$ and progesterone $<0 \cdot 1 \%$. The standard curve ranged from $0 \cdot 2$ to $25 \mathrm{pg} /$ tube, corresponding to a sensitivity of $10 \mathrm{pg} /$ $\mathrm{ml}$ plasma or $1 \mathrm{pg} / \mathrm{ml}$ plasma after concentration (dissolving in $100 \mu \mathrm{l}$ buffer only). The $\mathrm{ED}_{50}$ of the standard curve was $2 \mathrm{pg} /$ tube. Average intra- and inter-assay coefficients of variation were $6 \cdot 7 \%$ and $10 \cdot 5 \%$ respectively.

Determination of $\Delta 4$-androstenedione in blood plasma was performed using a commercial RIA kit (ref. 0674, Immunotech a. s., Prague, Czech Republic). Plasma samples $(300 \mu \mathrm{l})$ were extracted with ethyl ether, evaporated to dryness and taken into assay buffer. Biological extracts and standards were then incubated in duplicate in tubes coated with anti- $\Delta 4$-androstenedione antibodies using ${ }^{125}$ I labelled $\Delta 4$-androstenedione as a tracer. A calibration curve was established for the range $0-15 \mathrm{ng} / \mathrm{ml}$ $(0-52 \mathrm{nM})$. After incubation overnight at $4{ }^{\circ} \mathrm{C}$, the contents of the tubes were aspirated and tubes were measured and evaluated using a Berthold LB 2104 Multi Gamma Counter. The detection limit was $0.055 \mathrm{ng} / \mathrm{tube}$. Intraand inter-assay coefficients of variation $(\mathrm{CVs})$ were $5 \cdot 6 \%$ and $8.9 \%$ respectively. Details concerning performance of the assay, including androstenedione antiserum cross reactivities are given in Instructions for the Quantitative Determination of $\Delta 4$-Androstenedione, Ref. 0674, Immunotech, Marseille, France.

IGF-1 was determined by RIA after acid-ethanol extraction of $50 \mu \mathrm{l}$ blood plasma (Schams et al. 1992). Recombinant human IGF-1 (Lilly Company, Saint Louis, MO, USA) was used for iodination according to the lactoperoxidase method and as standard. Separation of bound and free hormone was accomplished by a combination of second-antibody technique with $4 \%$ polyethylene glycol. The assay was validated for fallow deer plasma by recovery studies (IGF-1 added to plasma samples before extraction, average recovery $89 \%$ ) and complete parallel displacement was observed between extracted samples and the standard curve. Intra- and inter-assay CVs were $<10 \%$ and $<16 \%$ respectively.

Concentrations of cortisol (4-pregnene-11 $\beta-17 \alpha-21-$ triol-3, 20-dione; Steraloids, Wilton, NH, USA) were 
measured with a competitive EIA (Sauerwein et al. 1991). The antibody was raised in a rabbit against cortisol21-hemisuccinate-BSA. Cross reactivities were: cortisol $100 \%$, cortisone $8 \%$, corticosterone $9 \cdot 5 \%$, prenisolone $18 \%$. Blood plasma was extracted with a 10 -fold volume of tert-butyl methyl ether. After freezing at $-60{ }^{\circ} \mathrm{C}$, extracts were decanted, evaporated and reconstituted. Interassay CV was between 7 and 14\%.

FSH was determined by a heterologous RIA in which pure ovine FSH was used in labelling, and the antiserum against ovine FSH was produced in a guinea pig (Schams et al. 1980). As a reference preparation, we used USDAbFSH-B1. The sensitivity was $5 \mathrm{ng} /$ tube, with a mean intra-assay $\mathrm{CV}$ of $7 \cdot 5 \%$ and interassay $\mathrm{CV}$ s between 11 and $17 \%$. The assay was validated for fallow deer plasma by recovery studies and dilution curves of fallow deer plasma run parallel to bovine standard.

LH was determined by a homologous bovine assay with no cross reactivity to other pituitary hormones (Schams \& Karg 1969, Schams et al. 1980). The reference preparation was a pure bovine pituitary extract prepared in our laboratory (LH-DSA with a biological activity of 1.0 times NIH-LH-S1). The assay was validated for fallow deer plasma by recovery studies of four different concentrations added to plasma. Average recovery was $96 \cdot 4 \pm 6 \cdot 4 \%$. Dilution curves of fallow deer plasma ran parallel to bovine standard. The sensitivity was $0.05 \mathrm{ng} /$ tube; intra-assay $\mathrm{CV}$ averaged $8 \cdot 2 \%$, and interassay CV was $10 \cdot 4-14 \%$.

\section{Statistical evaluation of the data}

All statistical analyses were performed with the aid of the Statistical Analysis System (SAS). For all designs that are unbalanced (i.e. the number of observations for the different combination of class variables is unequal), ANOVA cannot be used; hence, where appropriate, general linear model (GLM) was used instead (Cody \& Smith 1997). Class and model definitions and result characteristics, such as degrees of freedom (df) and $F$ value, are identical to those used with ANOVA (SAS System). The classes were 'Days after castration' (30 items for blood sampling between days -2 and 273), 'Group' (CA group, controls), 'Sample order' (1-12, expressing the order in which the animals were sampled), 'Buck' (12 individual deer). The classes 'Days after castration' and 'Buck' were nested within 'Group'. In presenting the results, we used adjusted means for main effects - that is, least-square means (LSmeans). These were computed for each class and differences between classes were tested by $t$-test. To elucidate possible relationships between antler size and hormone values, we used the data for the period when main antler elongation occurred (between days 64 and 169, see Fig. 3). For each buck, areas under the curve (AUC) were calculated for antler length, testosterone, androstenedione and IGF-1, multiplying the interval between sampling sessions (in days) by the mean value of the hormone calculated from the two successive sampling sessions. Relationships among hormones and between antler length and hormones were studied by computing residual Spearman correlation coefficients according to specific aspects described below.

\section{Results}

At castration, the two groups did not differ either in body weight (mean \pm s.E., CA group $43.75 \pm 0.99 \mathrm{~kg}, n=6$; controls $43.42 \pm 0.77 \mathrm{~kg}, n=6$ ) or in the weight of the removed testes (CA group 39.86 $\pm 1.67 \mathrm{~g}, n=6$, controls $40 \cdot 27 \pm 0 \cdot 79 \mathrm{~g}, n=6$, $t$-tests, NS). All animals cast their antlers in the period between days 12 and 22 after castration. Casting was not followed by immediate antler regrowth. New velvet antler growth was first observed more than 1 month after casting, around the time when new antlers usually start to develop in intact animals. For comparison, Fig. 1 gives data from a study on intact fallow bucks (Rolf \& Fischer 1990), in which fallow deer bucks of the same age as those in the present study were used. Compared with these animals, both our experimental groups showed premature casting. Furthermore, there was a long gap before the start of antler regrowth in the two castrate groups, but not the intact animals. The castrated deer started to regrow antlers earlier in the year (as a result of premature casting) than did the intact bucks, and they continued to grow them for longer. Testosterone concentrations in intact bucks increased well above the castrated value (almost 10 times) about 60 days before antler casting, and then decreased slowly, reaching a nadir (still above castrate value) just after casting and during the initial regrowth of the new antlers. Comparison with the intact bucks clearly demonstrated that the premature casting and early regrowth of antlers observed in our experimental animals were castration-induced events.

Antler regrowth occurred in all controls, and the antlers produced by these animals were much larger than those of the CA-treated castrates (mean \pm S.E., controls 275.83 \pm $29 \cdot 14 \mathrm{~mm}, n=6$; CA group $156 \cdot 75 \pm 49 \cdot 37 \mathrm{~mm}, n=6$; $t$-test, $t=2 \cdot 08, P<0 \cdot 03)$. Only four of the six CA-treated castrates initiated antler growth at the same time as the controls, and in the remaining two no regrowth was observed until day 196. At that time, unilateral (left side) antler formation started in one of these bucks, whereas in the other no antler growth at all occurred until the end of the experiment.

Because the class 'Sample order' appeared to be non-significant for all variables, it was omitted from the GLMs. Within 2 days after the start of CA treatment, testosterone concentrations in the CA group decreased to the level of the controls 4 days after castration (GLM, $F_{(69,356)}=2 \cdot 68, P<0 \cdot 001$; CA group, difference between days -2 (LSmeans \pm S.E., $1.03 \pm 0.11 \mathrm{ng} / \mathrm{ml}$ ) and 0 $(0 \cdot 08 \pm 0.11 \mathrm{ng} / \mathrm{ml}), \quad P<0 \cdot 001 ; \quad$ controls, difference 
Table 1 Results of GLM procedure for antler length and testosterone, androstenedione, IGF-1, cortisol, FSH and LH concentrations

\begin{tabular}{|c|c|c|c|c|c|c|c|c|}
\hline & \multicolumn{2}{|l|}{ Model } & \multicolumn{2}{|c|}{$\begin{array}{l}\text { Days after } \\
\text { castration (Group) }\end{array}$} & \multicolumn{2}{|l|}{ Group } & \multicolumn{2}{|c|}{ Buck (Group) } \\
\hline & $\begin{array}{l}d f=65332 \\
F\end{array}$ & $\mathrm{P}<$ & $\begin{array}{l}d f=54332 \\
F\end{array}$ & $\mathrm{P}<$ & $\begin{array}{l}\mathrm{df}=1332 \\
F\end{array}$ & $\mathrm{P}<$ & $\begin{array}{l}\mathrm{df}=10332 \\
F\end{array}$ & $\mathrm{P}<$ \\
\hline Antler length & $24 \cdot 61$ & 0.001 & $22 \cdot 4$ & $0 \cdot 001$ & $168 \cdot 1$ & 0.001 & $21 \cdot 5$ & 0.001 \\
\hline Testosterone & $6 \cdot 96$ & $0 \cdot 001$ & $3 \cdot 54$ & $0 \cdot 001$ & $186 \cdot 2$ & $0 \cdot 001$ & $7 \cdot 81$ & $0 \cdot 001$ \\
\hline Androstenedione & 14.93 & $0 \cdot 001$ & $7 \cdot 98$ & $0 \cdot 001$ & $428 \cdot 3$ & $0 \cdot 001$ & $10 \cdot 9$ & $0 \cdot 001$ \\
\hline IGF-1 & $40 \cdot 24$ & $0 \cdot 001$ & $47 \cdot 1$ & $0 \cdot 001$ & $0 \cdot 18$ & NS & $7 \cdot 93$ & $0 \cdot 001$ \\
\hline Cortisol & $2 \cdot 11$ & $0 \cdot 001$ & $1 \cdot 69$ & $0 \cdot 01$ & $16 \cdot 98$ & 0 & $3 \cdot 04$ & $0 \cdot 001$ \\
\hline $\mathrm{FSH}$ & $23 \cdot 97$ & $0 \cdot 001$ & $17 \cdot 2$ & $0 \cdot 001$ & $537 \cdot 2$ & 0 & $9 \cdot 22$ & $0 \cdot 001$ \\
\hline $\mathrm{LH}$ & $16 \cdot 97$ & 0.001 & $6 \cdot 81$ & $0 \cdot 001$ & $568 \cdot 9$ & 0 & $16 \cdot 6$ & $0 \cdot 001$ \\
\hline
\end{tabular}

between days $0 \quad(1 \cdot 02 \pm 0 \cdot 11 \mathrm{ng} / \mathrm{ml})$ and $4 \quad(0 \cdot 08 \pm$ $0 \cdot 11 \mathrm{ng} / \mathrm{ml}), P<0 \cdot 001$; difference between the groups at day $0, P<0 \cdot 001)$. As CA treatment and castration resulted in more than 10 times lower testosterone concentrations compared with those at the start of the experiment, only the data for day 4 and later were used for further analysis. The number of the class 'Days after castration' items thus declined to 28 .

Models and all classes in these models for antler length and all hormones showed high, significant variation (Table 1). The highly significant influence of individual bucks on the hormonal levels (class 'Buck' nested within 'Group') made it necessary to incorporate this effect into the model.

Testosterone concentrations in the controls exceeded those in the CA-treated bucks throughout the period from day 4 to day 273 (class 'Group' in Table 1, Fig. 2, top left). Hormone concentrations fluctuated over the course of the experiment (class 'Days after castration' nested within 'Group' in Table 1). The differences between groups were especially pronounced during the time of antler growth
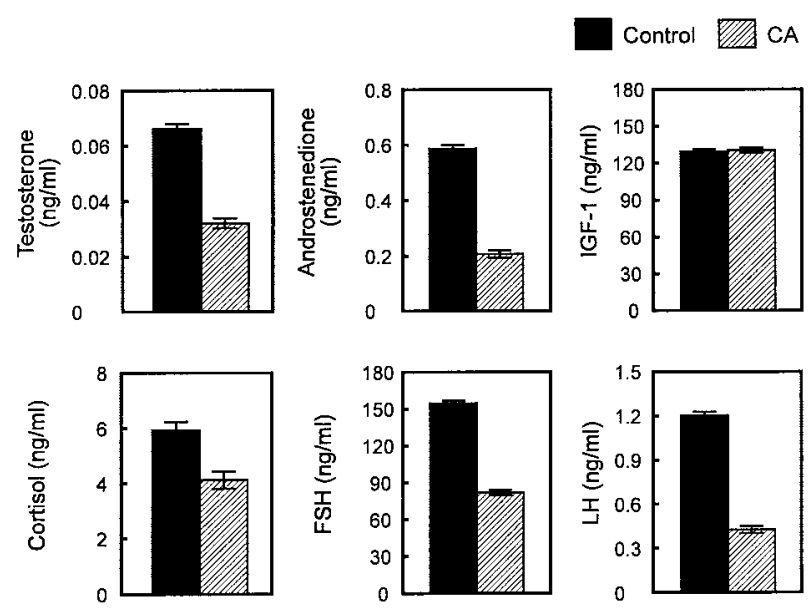

Figure 2 Comparison between CA and Control groups in total concentrations of testosterone, androstenedione, IGF-1, cortisol, $\mathrm{FSH}$ and $\mathrm{LH}$ (LSmeans \pm S.E.) between days 4 and 273. except on day 106 (Fig. 3). In both groups, testosterone concentrations declined until day 28, then gradually increased and reached a temporary peak at day 77 , the sampling date following that when first antler growth was detected in the animals. Subsequently, a transient decrease in testosterone concentrations was observed. When comparing the testosterone levels for day 77 with those of the preceding and the following sampling dates, respectively, the differences approached significance in the CA group $(P=0 \cdot 09, P=0 \cdot 07)$ and reached significance in the controls $(P=0.03, P=0.05)$. During that interval, testosterone concentrations in controls were much greater than those in CA group (at least $P<0 \cdot 01$ ). A short-term increase in androgens occurred also in the deer that did not develop, or only belatedly developed, antlers.

Androstenedione concentrations showed a pattern similar to those of testosterone (Fig. 3). Concentrations were greater in controls than in the CA group (class 'Group' in Table 1, Fig. 2, top middle). A temporary increase in androstenedione concentrations occurred before the onset of antler growth in controls, but not in the CA group.

IGF-1 concentrations did not show any difference between the two groups (class 'Group' in Table 1, Fig. 2, top right). A marked increase in the concentrations occurred between days 106 and $119(P<0 \cdot 001$ in both groups) - that is, after the bucks were released into the outdoor paddocks. This increase in IGF-1 concentrations was associated with a remarkable spurt in antler growth rate in both groups (Fig. 3).

Plasma cortisol concentrations differed between the two groups (class 'Group' in Table 1, Fig. 2, bottom left); however, no relationship between cortisol concentrations and antler growth was apparent (Fig. 3).

Plasma FSH and LH concentrations in the control bucks exceeded those for the CA-treated castrates over almost the entire study period (Fig. 3, Fig. 2 bottom middle and right). In the untreated castrates, a post-castration increase in the concentrations of both gonadotrophins was noted. After cessation of CA treatment, the values for the two groups tended to equalize. 


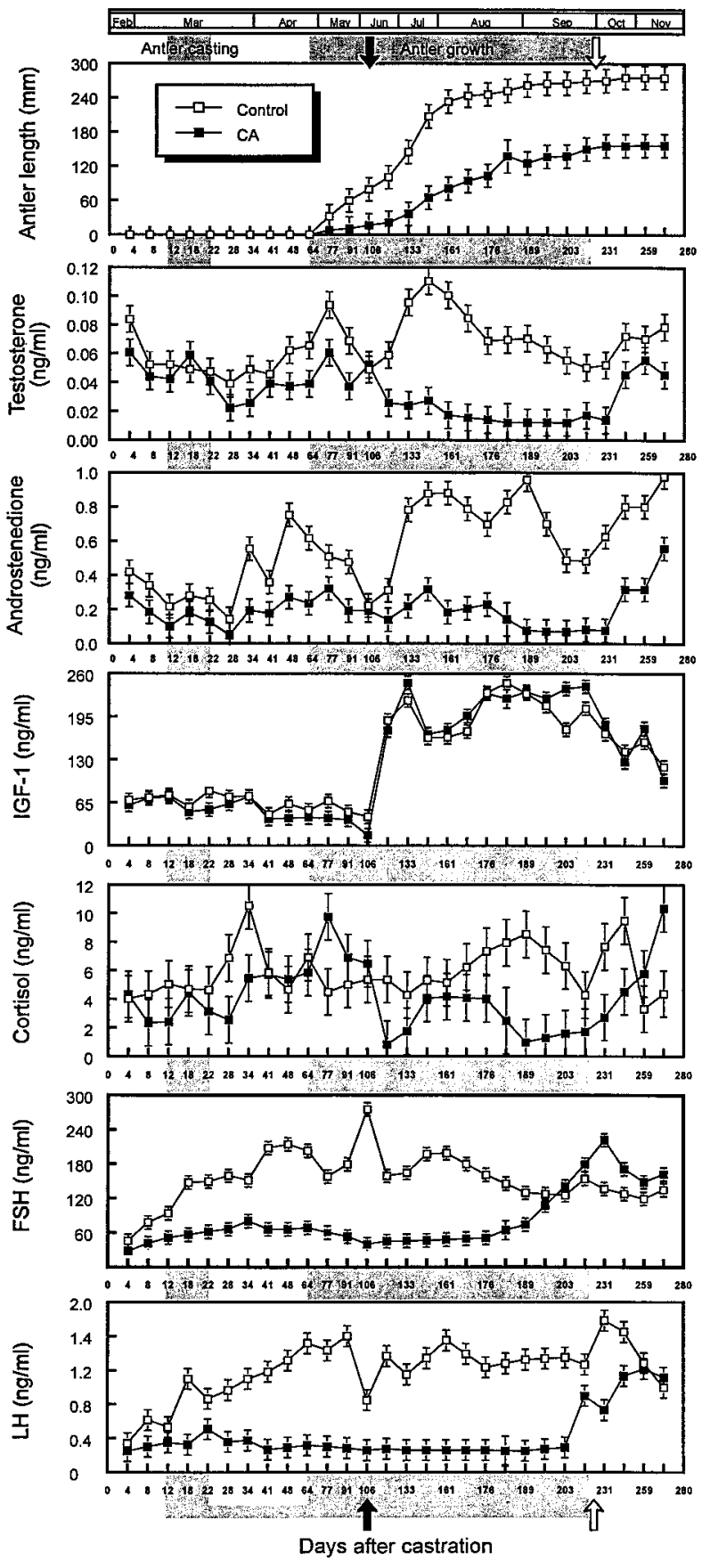

Figure 3 Antler length and testosterone, androstenedione, IGF-1, cortisol, FSH and $\mathrm{LH}$ concentrations (LSmeans \pm S.E.) between days 4 and 273 in CA and control groups. (Open arrows indicate the time of the last treatment of CA and castor oil; black arrows indicate the time when the animals were moved into the outdoor paddock.)

For the pooled deer $(n=12)$, AUC for antler length was positively correlated with AUC for plasma testosterone concentration. An almost significant trend
Table 2 Residual Spearman correlation coefficients between AUCs of testosterone, androstenedione, and IGF-1 concentrations from 64 to 169 days after castration and the area of the antler length curve, showing that antler length was related to testosterone and possibly androstenedione concentrations, but not those of IGF-1
Testosterone Androstenedione IGF-1

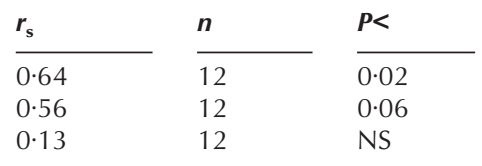

for a positive correlation was also found for AUCs for antler length and androstenedione concentrations. In contrast, AUCs for antler length and IGF-1 were not correlated (Table 2). Antler length thus was related to testosterone and possibly androstenedione concentrations, but not to those of IGF-1. While the two androgens were intercorrelated $\left(\mathrm{r}_{\mathrm{s}}=0 \cdot 88, n=12, P<0 \cdot 001\right)$, neither testosterone $\left(r_{\mathrm{s}}=-0 \cdot 15, n=12\right.$, NS), nor androstenedione $\left(r_{s}=-0 \cdot 09, n=12, N S\right)$ correlated with IGF-1.

\section{Discussion}

CA treatment of castrated fallow bucks resulted in significantly reduced antler growth in addition to reduced androgen and gonadotrophin concentrations, when compared with untreated castrates (controls). In contrast, no difference in plasma IGF-1 concentrations occurred between the two groups. The increase in gonadotrophin concentrations in the control group was the expected feedback reaction typically observed after castration (Bubenik et al. 1982). The much lower concentrations in the CA-treated castrates reflect a well known endocrine effect of CA, which, in addition to a blocking of the androgen receptors, also exerts strong progestagenic effects and therefore suppresses release of hypothalamic gonadotropin-releasing hormone and subsequent LH/FSH secretion by the adenohypophysis (Neumann 1994, Neumann \& Töpert 1986).

The fact that, in the CA-treated castrates also, androstenedione concentrations were lower than in controls indicates that CA treatment also reduced ACTH secretion by the pituitary (cf. Girard \& Baumann 1976) and, in consequence, androgen production by the adrenals. Thus, in the CA-treated castrates, both gonadotrophin and adrenal androgen production were strongly suppressed, in addition to the blocking of the androgen receptors. Thereby, we created an experimental situation in which we could compare the influence of residual low androgen concentrations of adrenal origin (controls) on antler growth with the effects of an almost complete inhibition of any androgen action (CA group).

Using this approach, we first addressed the question whether the onset of antler regrowth is triggered by a 
short-term pulse of androgens. Indeed, in both groups we found a temporary increase in testosterone concentrations around the time of the onset of antler regrowth, the elevation being more pronounced in the control bucks. However, androstenedione concentrations did not show such a clear relation with the start of antler regrowth. Thus, on the basis of our results, although the substance of our first hypothesis is indicated, a definitive conclusion as to its validity could not been achieved.

Second, we tested if the growth process itself requires low concentrations of androgens. Antlers produced were much larger and androgen concentrations were significantly greater in controls than in the CA bucks. As two of the six CA-treated animals grew almost no antlers, we conclude that, in fallow deer, a minimum threshold concentration of androgens, testosterone in particular, is a necessary prerequisite for normal antler growth to occur. Moreover, within the low range of plasma testosterone concentrations recorded in our experimental animals, we were able to demonstrate an increase in an antler growth rate with increasing testosterone concentrations - that is, a dose-related response of the antlers to testosterone. Finally, it can be hypothesised that the already very low androgen concentrations present in the CA-treated animals were not fully active, because of the androgen receptor blockade exercised by CA. This means that the differences in androgen action at target sites were probably more pronounced between the two groups than is apparent by comparing plasma androgen concentrations.

During the initial stage of antler growth (days 64 to 106), IGF-1 concentrations were low and even tended to decrease. Furthermore, IGF-1 values did not differ between controls and the CA-treated castrates, despite the differences in antler growth rate between the two groups. This is seen as evidence that, under the experimental conditions of our study, circulating IGF-1 was not the primary factor determining antler growth rate and, in consequence, final antler size. This statement is not intended to deny the decisive role of IGF-1 as a promoter of antler growth. In a series of studies, it has been clearly shown that IGF-1 strongly stimulates antler growth, and that plasma IGF-1 levels play an important role in determining antler size (e.g., Suttie et al. 1989, 1994). However, in the present study no significant differences in IGF-1 concentrations were observed between the two groups, indicating that, under the given experimental conditions, circulating IGF-1 concentrations were not the ultimate factors determining antler growth rate and final antler size.

Westley \& May (1994) reviewed the evidence that steroids modulate cell proliferation by interacting with the IGF signal transduction pathway. A growth promoting effect of steroids can be brought about by increasing the production of IGF-1, which then acts as an autocrine, paracrine or endocrine growth factor. It has further been demonstrated that oestrogens increase the responsiveness of human breast cancer cells to IGF, presumably by upregulating the type 1 IGF-receptor (Stewart et al. 1990), in addition to the resulting components of the IGF signal-transduction pathway. On the basis of these findings and the results of the present study, it could be hypothesized that a possible role of low concentrations of testosterone in antler growth might be to sensitize antler cells (mesenchymal cells and chondroblasts of the antler tip) to the stimulating (mitogenic) effect of IGF-1. Threshold concentrations of androgens may also have an indirect effect on the production of antlers. Via their general anabolic action (Catlin et al. 1997), androgens may be essential for maintaining the synthesis of IGF-1: stimulation of IGF-1 production was reported after testosterone treatment by Craft \& Underwood (1984). The rate of production of IGF-1 in the liver may then determine the intensity of antler growth (Suttie et al. 1989, 1994).

Elliott et al. (1996) treated intact fallow bucks with high doses of testosterone in mid-antler growth and measured labelled IGF-1 uptake in vitro in antler tip sections. Testosterone administration caused a significant decline in the rate of IGF-1 binding in dermis, reserve mesenchyme/ perichondrium and chondroblasts. The authors concluded that testosterone reduces antler growth by reducing IGF-1 binding to the type-1 receptor. This is in agreement with the established negative role of greater plasma concentrations of androgens on antler growth (e.g., Goss 1968). In this context, we wish to emphasize that our study was not designed to assess the role of androgens in antler growth of intact bucks, and that our conclusions about a stimulating effect of androgens on antler growth clearly cannot be extended beyond the range of plasma androgen concentrations observed in our experimental animals.

Except for the study by Bubenik (1982) on castrated white-tailed deer, so far all experiments using CA in roe, fallow and red deer were performed on intact animals (Schams et al. 1986, Kierdorf et al. 1993, Kolle et al. 1993, Suttie et al. 1995). In the latter studies, CA treatment induced premature casting and delayed antler maturation and velvet shedding. However, antler growth was apparently normal and the antlers produced were of species-specific shape. On the basis of the results of the present study it may be assumed that, in these cases, the amounts of physiologically active testosterone were high enough to meet the minimum requirements for normal antler growth. This may plausibly explain inconsistencies in the literature. In red deer stags, Suttie et al. (1995) reported significantly longer antlers in a group treated with $350 \mathrm{mg} \mathrm{CA} /$ week than in either the control group or a the group receiving $150 \mathrm{mg} \mathrm{CA} /$ week. This was caused by extending the duration of antler growth. Hence, the CA treatment prevented onset of the suppressive testosterone function in the final phase of antler growth and delayed mineralization; however, it probably did not eliminate androgen stimulatory function in initiation of an antler regrowth. In another part of the same study (Suttie et al. 
1995), testosterone implants were used to prevent the gradual decline in plasma testosterone concentrations normally observed during winter. Implants were removed 3 weeks before the anticipated date of antler casting. The implants significantly increased plasma testosterone concentrations and subsequent antler growth (expressed as a proportional increase compared with the previous year) compared with untreated controls.

Because, in the present study, high doses of CA were given to the experimental animals, it might be argued that the reduced growth observed in the treatment group was due to a sex-steroid mimicking (i.e. an inhibiting) effect exercised by the antiandrogen. Because CA is a hydroxyprogesterone derivative (Neumann 1994) and it has been shown that high doses of progesterone can induce velvet shedding in castrated red deer (Jaczewski 1979), this argument has to be considered seriously. However, a number of our observations are inconsistent with the above hypothesis. Thus, if it were correct, we would have expected a delay in antler casting, or no casting at all, in the CA group, treated with high doses $(1000 \mathrm{mg})$ at 2-day intervals, but all CA-treated animals cast their antlers in the same timespan as the controls. Furthermore, we did not observe velvet shedding from the regrowing antlers in the CA group, which would have been expected if the CA exercised an effect analogous to those of sex-steroids. During this period, the animals were dosed with $1000 \mathrm{mg}$ CA per week. According to Neumann (1994), treatment of 100 or $200 \mathrm{mg}$ CA per day was effective in suppressing sexuality in men with deviant sexual behaviour. Accessory sexual gland function and spermatogenesis were completely inhibited in these patients. Those on the higher dosage regime received a dose of CA per kg body weight (on a per week basis) in the same range as that applied to the fallow bucks after antler casting. Apparently no side effects were observed in the men treated long term that were indicative of a sex-steroid mimicking effect of the CA.

To the best of our knowledge, there exists no published information on IGF-1 concentrations of fallow deer around the time of antler casting and regrowth. The increase in IGF-1 concentration during antler growth observed in the fallow deer matches findings in red deer (Suttie et al. 1985, 1988), roe deer (Schams et al. 1992), and pudu (Reyes et al. 1997), but not in male and female reindeer (Bubenik et al. 1998). The sudden increase in IGF-1 levels and, in consequence, antler growth rate upon release of the experimental animals into the outdoor paddock most probably reflect changes either in energy supply (Thissen et al. 1994) or in the light regime. The same conditions in the barn could also have been the cause for the delayed onset of an antler regrowth in both groups because, in fallow bucks kept outdoors, castration-induced casting was immediately followed by antler regrowth (Kierdorf et al. 1995). In reindeer, Suttie et al. (1991) found that 6-8 weeks after the onset of the study, calves exposed to a regime of $16 \mathrm{~h}$ light : $8 \mathrm{~h}$ darkness showed a significant increase in plasma IGF-1, whereas the concentrations in calves exposed to $8 \mathrm{~h}$ light : $16 \mathrm{~h}$ darkness did not increase. This suggested that IGF-1 secretion is regulated by the photoperiod.

In conclusion, the results of the present study indicate a biological role of low concentrations of androgens in antler growth of fallow deer, in addition to the well known role of higher androgen levels for the timing of antler cycle (retaining of hard antlers, antler maturation and velvet shedding). Thus, a plasma androgen concentration above a minimal threshold value seems to be a necessary prerequisite for antler growth at a normal rate. This androgen effect is not mediated via circulating IGF-1 concentrations. A possible role of low androgen concentrations may be the sensitization of antler cells to the stimulating effects of IGF-1, but so far this has not been demonstrated experimentally. Therefore, in vivo and in vitro studies addressing the question of a potential dual role of androgens in antler growth are to be strongly encouraged.

\section{Acknowledgements}

For the generous gift of the CA used in this study, we are very much indebted to Schering AG (Berlin, Germany). We appreciate greatly the donation of reference preparation for FSH from the USDA Animal Hormone Program, Beltsville, MD, USA. We are grateful to Drs Jimmy Suttie and Chunyi Li for their constructive comments, discussions and providing us with unpublished information. We also greatly appreciate the constructive comments given by the scientific editor of Journal of Endocrinology and two anonymous reviewers. The technical assistance of Dalibor Zaorálek, MVD, Petr Janovský, Anna Waldhansová and Bohumila Krupková is gratefully acknowledged. The study was supported by a grant from the Czech Grant Agency (505/95/0291). The investigation was approved by the local ethics committee.

\section{References}

Bartoš L 1980 The date of antler casting, age and social hierarchy relationships in the red deer stag. Behavioural Processes 5 293-301.

Bartoš L 1990 Social status and antler development in red deer. In Horns, Pronghorns and Antlers: Evolution, Morphology and Social Significance, pp 442-459. Eds GA Bubenik \& AB Bubenik. New York: Springer-Verlag.

Blottner S, Hingst O \& Meyer HHD 1996 Seasonal spermatogenesis and testosterone production in roe deer (Capreolus capreolus). Journal of Reproduction and Fertility 108 299-305.

Brown RD, Cowan RL \& Griel LC 1978 Correlation between antler and long bone relative bone mass and circulating androgens in white-tailed deer (Odocolieus virginianus). American Journal of Veterinary Research 39 1053-1056.

Bubenik GA 1982 Endocrine regulation of the antler cycle. In Antler Development in Cervidae, pp 73-107. Ed RD Brown. Kingsville, Texas: Caesar Kleberg Wildlife Research Institute. 
Bubenik GA 1990 Neuroendocrine regulation of the antler cycle. In Horns, Pronghorns, and Antlers: Evolution, Morphology, Physiology, and Social Significance, pp 265-297. Eds GA Bubenik \& AB Bubenik. New York: Springer-Verlag.

Bubenik GA, Morris JM, Schams D \& Claus A 1982 Photoperiodicity and circannual levels of $\mathrm{LH}, \mathrm{FSH}$, and testosterone in normal and castrated male, white-tailed deer. Canadian Journal of Physiology and Pharmacology 60 788-793.

Bubenik GA, Schams D, White RG, Rowell J, Blake J \& Bartoš L 1998 Seasonal levels of metabolic hormones and substrates in male and female reindeer (Rangifer tarandus). Comparative Biochemistry and Physiology C-Pharmacology Toxicology and Endocrinology 120 307-315.

Catlin DH, Hatton CH \& Starcevic SH 1997 Issues in detecting abuse of xenobiotic anabolic steroids and testosterone by analysis of athletes' urine. Clinical Chemistry 43 1280-1288.

Cody RP \& Smith JK (1997) Applied Statistics and the SAS Programming Language. Upper Saddle River, New Jersey: Prentice-Hall, Inc.

Craft WH \& Underwood LE 1984 Effects of androgens on plasma somatomedin-C insulin-like growth factor 1 responses to growth hormone. Clinical Endocrinology 20 549-703.

Elliott JL, Oldham JM, Asher GW, Molan PC \& Bass JJ 1996 Effect of testosterone on binding of insulin-like growth factor-I (IGF-I) and IGF-II in growing antlers of fallow deer (Dama dama). Growth Regulation 6 214-221.

Girard J \& Baumann JB 1976 Secondary adrenal insufficiency due to cyproterone acetate. Journal of Endocrinology 69 13-14.

Goss RJ 1968 Inhibition and shedding of antlers by sex hormones. Nature 220 83-85.

Goss RJ 1983 Deer Antlers: Regeneration, Function and Evolution. New York: Academic Press.

Jaczewski Z 1979 Die Auswirkungen von Progesteron auf den Geweihzyklus beim Rotwild (Cervus elaphus L.). Zeitschrift für Jagdwissenschaft 25 150-159.

Kierdorf U, Schultz M \& Fischer K 1993 Effects of an antiandrogen treatment on the antler cycle of male fallow deer (Dama dama L.) Journal of Experimental Zoology 266 195-205.

Kierdorf U, Kierdorf H \& Knuth S 1995 Effects of castration on antler growth in fallow deer Dama dama. Journal of Experimental Zoology 273 33-43.

Kolle R, Kierdorf U \& Fischer K 1993 Effects of an antiandrogen treatment on morphological characters and physiological functions of male fallow deer (Dama dama L.). Journal of Experimental Zoology 267 288-298.

Li C, Littlejohn RP \& Suttie JM 1999 Effects of insulin-like growth factor 1 and testosterone on the proliferation of antlerogenic cells in vitro. Journal of Experimental Zoology 284 82-90.

Neumann F 1994 The antiandrogen cyproterone acetate: discovery, chemistry, basic pharmacology, clinical use and tool in basic research. Experimental and Clinical Endocrinology 102 1-32.

Neumann F \& Töpert M 1986 Pharmacology of antiandrogens. Journal of Steroid Biochemistry 25 885-895.

Reyes E, Bubenik GA, Lobos A, Schams D \& Bartoš L 1997 Seasonal levels of cortisol, IGF-1 and triiodothyronine in adult male pudu (Pudu puda). Folia Zoologica 46 109-116.

Rivest RW, Lynch HJ, Ronsheim PM \& Wurtman RJ 1981 Effect of light intensity on regulation of melatonin secretion and drinking behavior in the albino rat. In Melatonin: Current Status and Perspectives, pp 119-123. Eds N Birau \& W Schloot. New York: Pergamon Press.

Rolf HJ \& Fischer K 1990 Serum testosterone (T) and 5-alphadihydrotestosterone (DHT) in male fallow deer (Dama-dama L) seasonality and age dependence. Comparative Biochemistry and Physiology A-Comparative Physiology 95A 445-452.

Sadighi M, Haines SR, Skottner A, Harris AJ \& Suttie JM 1994 Effects of insulin-like growth factor-I (IGF-I) and IGF-II on the growth of antler cells in vitro. Journal of Endocrinology 143 461-469.
Sauerwein H, Dürsch I \& Meyer HHD 1991 Quantitation of glucocorticoid receptors in bovine skeletal muscle: topographical distribution, sex effect and breed comparisons. Journal of Steroid Biochemistry and Molecular Biology 39 941-945.

Schams D \& Karg H 1969 Radioimmunologische Bestimmung von Prolactin in Blutserum vom Rind. Milchwissenschaft 24 262-265.

Schams D, Barth D \& Karg H 1980 LH, FSH and progesterone concentrations in peripheral plasma of the female roe deer (Capreolus capreolus) during the rutting season. Journal of Reproduction and Fertility 60 109-114.

Schams D, Barth D \& Karg H 1986 Is antler growth in adult roe deer (Capreolus capreolus) influenced by treatment with oestradiol-17 $\beta$, an antiandrogen, or a prolactin inhibitor? In Endocrine Regulations as Adaptive Mechanisms to the Environment, pp 475-482. Eds I Assenmacher \& J Boissin. Paris: C.N.R.S.-C.E.B.A.S.

Schams D, Barth D, Heinze-Mutz E-M, Pflaum G \& Karg H 1992 Antler growth in roe deer: effects of casting and correlations with growth hormone and insulin like growth factor I. In The Biology of Deer, pp 505-510. Ed RD Brown. New York: Springer-Verlag.

Sempéré AJ \& Boissin J 1982 Neuroendocrine and endocrine control of the antler cycle in roe deer. In Antler Development in Cervidae, pp 109-122. Ed RD Brown. Kingsville, Texas: Caesar Kleberg Wildlife Research Institute.

Stewart AI, Johnson MD, May FEB \& Westley BR 1990 Role of insulin-like growth factors and the type 1 insulin-like growth factor receptor in the estrogen-stimulated proliferation of human breast cancer cells. Journal of Biological Chemistry 265 21172-21178.

Suttie JM, Gluckman PD, Butler JH, Fennessy PF, Corson ID \& Laas FJ 1985 Insulin-like growth factor 1 (IGF-1) antler-stimulating hormone. Endocrinology 116 846-848.

Suttie JM, Fennessy PF, Gluckman PD \& Corson ID 1988 Elevated plasma IGF-1 levels stags prevented from growing antlers. Endocrinology 122 3005-3007.

Suttie JM, Fennessy PF, Corson ID, Laas FJ, Crosbie SF, Butler JH \& Gluckman PD 1989 Pulsatile growth hormone, insulin-like growth factors and antler development in red deer (Cervus elaphus scoticus) stags. Journal of Endocrinology 121 351-360.

Suttie JM, White RG, Breier BH \& Gluckman PD 1991 Photoperiod associated changes in insulin-like growth factor-I in reindeer. Endocrinology 129 679-682.

Suttie JM, Fennessy PF, Corson ID, Veenvliet BA, Littlejohn RP \& Lapwood KR 1992 Seasonal pattern of luteinizing hormone and testosterone pulsatile secretion in young adult red deer stags (Cervus-elaphus) and its association with the antler cycle. Journal of Reproduction and Fertility 95 925-933.

Suttie JM, Li CY, Sadighi M, Gunn J \& Fleming JS 1994 Physiological control of antler growth. In Recent Developments in Deer Biology, pp 189-196. Ed JA Milne., Craigiebuckler, Aberdeen: Macaulay Land Use Research Institute and Edinburgh: Moredun Research Institute.

Suttie JM, Fennessy PF, Lapwood KR \& Corson ID 1995 Role of steroids in antler growth of red deer stags. Journal of Experimental Zoology 271 120-130.

Thissen JP, Ketelslegers JM \& Underwood LE 1994 Nutritional regulation of the insulin-like growth factors. Endocrine Reviews $\mathbf{1 5}$ 80-101.

Westley BR \& May FEB 1994 Role of insulin-like growth factors in steroid modulated proliferation. Journal of Steroid Biochemistry and Molecular Biology 51 1-9.

Received 26 October 1998

Revised manuscript received 23 February 1999

Final revision received 19 July 1999

Accepted 10 August 1999 